\title{
ESTUDO DA ETAPA DE CEMENTAÇÃO NO ESTADO SÓLIDO DE UM AÇO AISI 5115 PARA APLICAÇÕES COM RESISTÊNCIA AO DESGASTE SUPERFICIAL *
}

\author{
Tainan Ferreira Muniz ${ }^{1}$ \\ Letícia Maria de Melo Silva Cheloni \\ Milena Kellen Oliveira Mendes ${ }^{3}$
}

\begin{abstract}
Resumo
Visando atender à demanda de materiais de engenharia que apresentem elevada resistência ao desgaste sem prejudicar sua ductilidade, o presente artigo objetivou avaliar a influência dos tempos de cementação em meio sólido nas propriedades mecânicas de um aço baixo carbono submetido ao tratamento. Adotou-se diferentes tempos de estágio, a saber $6 \mathrm{~h}, 11 \mathrm{~h}$ e $24 \mathrm{~h}$, fixando-se a temperatura a $900^{\circ} \mathrm{C}$. Além disso, a fim de verificar a validade dos experimentos e compará-los às previsões teóricas, estimou-se, pela Lei de Fick, a profundidade da camada cementada. Métodos mais práticos, como a elaboração de perfis de dureza e a análise de microestruturas, reafirmaram as previsões e indicaram que a profundidade da camada cementada aumenta com o tempo de exposição das amostras à atmosfera adequada. Palavras-chave: Tempo de cementação; Profundidade de camada cementada; Lei de Fick; Aço AISI 5115.
\end{abstract}

\section{STUDY OF THE CEMENTATION IN A SOLID ENVIRONMENT OF AN AISI 5115 STEEL FOR SUPERFICIAL WEAR RESISTANCE APPLICATIONS}

\begin{abstract}
Aiming to meet the demand of engineering materials that presents high wear resistance without impair ductility, this article intended to evaluate the influence of carburizing periods in a solid environment on the mechanical properties of a low carbon steel submitted to this treatment. Different periods were adopted, $6 \mathrm{~h}, 11 \mathrm{~h}$ and $24 \mathrm{~h}$, all of them at the same temperature $\left(900^{\circ} \mathrm{C}\right)$. Besides that, in order to verify the viability of the experiments and compare them with the theoretical predictions, it was estimated, by Fick's Law, the depth of the cemented layer. More practical methods, like the elaboration of hardness profiles and the analysis of the microstructures, reaffirmed the predictions and indicated that the depth of the cemented layer increases along the time of exposition of the samples to the adequate atmosphere.

Keywords: Carburizing times; Depth of the cemented layer; Fick's law; Steel AISI 5151.

1 Mestranda em Engenharia de Materiais, Estudante, REDEMAT, Universidade Federal de Ouro Preto, Ouro Preto, Minas Gerias, Brasil.

2 Mestranda em Engenharia de Materiais, Estudante, REDEMAT, Universidade Federal de Ouro Preto, Ouro Preto, Minas Gerias, Brasil.

3 Mestranda em Engenharia Aeronáutica, Estudante, Instituto Tecnológico de Aeronáutica, São José dos Campos, São Paulo, Brasil
\end{abstract}




\section{INTRODUÇÃO}

Dentre as diversas demandas das engenharias, peças como engrenagens, mancais, pistas de rolamento, eixos roscados e de comando de válvulas, entre outros, são amplamente utilizados. Esses componentes precisam atender propriedades mecânicas específicas, como alta dureza e resistência ao desgaste superficial, apresentando, ao mesmo tempo, um núcleo dúctil e tenaz $[1,2,3]$. As técnicas de processamento que compõem a engenharia de superfície são métodos atrativos para assegurar essas propriedades mecânicas aos materiais [4].

Entre esses métodos destacam-se os tratamentos termoquímicos, que objetivam o endurecimento superficial de ligas metálicas por meio da alteração da composição química na região de interesse [3]. Assim, essa técnica modifica a estrutura do material base e, consequentemente, suas propriedades mecânicas [5].

Os tratamentos termoquímicos são controlados por difusão, sendo considerados processos termicamente ativados [4]. A aplicação de calor no meio apropriado leva à alteração de composição química até uma certa profundidade no material. A extensão e as propriedades dessa camada dependem da temperatura de aquecimento e do tempo de permanência selecionados para o tratamento dos componentes [3].

Os processos mais comuns de endurecimento superficial são a cementação, nitretação e carbo-nitretação. Estes tratamentos e podem ser conduzidos em meio sólido, líquido, gasoso ou plasma, contendo um ou mais elementos químicos reativos como carbono, nitrogênio ou ambos $[5,3,1]$.

A cementação, objeto de estudo deste artigo, é um processo de adição de carbono à a superfície de aços baixo carbono a temperaturas acima da zona crítica. Nesta região, normalmente entre $850^{\circ} \mathrm{C}$ a $950^{\circ} \mathrm{C}$, a austenita é a estrutura estável, condição em que apresentaf alta solubilidade de carbono, permitindo sua difusão no material $[1,3,6]$.

Os processos de cementação podem ocorrer por via sólida, na qual a fonte de carbono é um sólido, via líquida, cuja fonte é líquida, ou via gasosa, em que a fonte é a atmosfera. O método via sólida é mais empregado, devido à a facilidade da técnica de execução, menor custo de produção e menor ocorrência de empenamento das peças. Nessa técnica, as peças de aço são armazenadas em caixas metálicas; resistentes ao calor. Seu interior é preenchido por uma mistura carburizante, composta normalmente por carvão ou coque e ativadores, que fornecerá o carbono a ser difundido para o interior do aço [3].

O controle do processo é feito substancialmente pela difusão do carbono para o interior do material, fenômeno que pode ser avaliado pela resolução simplificada da segunda Lei de Fick, descrita pela Equação 1:

$$
\frac{C x-C o}{C s-C o}=1-\operatorname{erf} \frac{x}{2 \sqrt{D t}}
$$

Em que, Cs, Co e Cx são as porcentagens de carbono na superfície, inicial e à uma distância $x$ da periferia, erf é a função de erro de Laplace, $x$ a distância à periferia, $t o$ tempo de cementação e D o coeficiente de difusão do carbono na austenita. Este último é calculado utilizando-se a Equação 2:

$$
D=D o \cdot e^{-Q / R T}
$$


$\mathrm{Na}$ qual, Do é a constante do sistema, dada em $\mathrm{m}^{2} / \mathrm{s}, \mathrm{Q}$ é a energia de ativação, dada em J/mol, R a constante dos gases, em J/mol x K, e T a temperatura de cementação, dada em $\mathrm{K}[1,7]$.

Após a cementação, os aços são submetidos aos tratamentos térmicos de têmpera e revenimento. O primeiro é realizado para aumentar a dureza e resistência à tração do material na camada superficial. Devido à maior concentração de carbono, a austenita dessa região é transformada em martensita [8,2]. Por sua vez, o revenimento é realizado para aliviar as tensões residuais da têmpera, aumentando a tenacidade do material e a resistência ao trincamento [1,2].

A alteração na estrutura do material ocorre devido à modificação parcial da composição química e posteriores tratamentos térmicos supracitados. A camada cementada normalmente possui uma estrutura martensítica, enquanto o núcleo é composto de perlita e ferrita [8,2]. Tais modificações estruturais geram a combinação de propriedades mecânicas desejadas, originando componentes superficialmente resistentes sem comprometer a ductilidade total da peça [1,3].

Considerando a importância da combinação de propriedades mecânicas em materiais de engenharia, visou-se avaliar o efeito da aplicação de tratamentos termoquímicos de cementação no estado sólido de um aço AISI 5115, objetivando determinar as possíveis correlações existentes entre dimensão teórica da camada cementada, a estrutura de sua superfície e seus valores de dureza.

\section{MATERIAIS E MÉTODOS}

\subsection{Materiais}

As amostras utilizadas nesse trabalho foram extraídas de uma barra de aço AISI 5151 , cujo diâmetro é de $20 \mathrm{~mm}$. Dessa barra, foram cortados corpos de prova de aproximadamente $40 \mathrm{~mm}$ de comprimento. A especificação química do aço em questão está apresentada na Tabela 1 [9].

Tabela 1. Especificação química do aço estudado neste trabalho (\% em massa).

\begin{tabular}{cccc}
\hline Elemento & $\%$ & Elemento & $\%$ \\
\hline $\mathrm{C}$ & 0,16 & $\mathrm{Mn}$ & 1,15 \\
\hline $\mathrm{Si}$ & 0,40 & $\mathrm{Cr}$ & 0,95 \\
\hline
\end{tabular}

\subsection{Procedimentos Experimentais}

\subsubsection{Tratamentos Termoquímicos}

O tratamento termoquímico realizado foi de cementação no estado sólido. Cada conjunto de amostra, A, B e C, foi colocado no centro de uma caixa contendo cemento, preservando os mesmos espaçamentos laterais, superior e inferior. $\mathrm{O}$ cemento foi composto por $10 \%$ de coque, $10 \%$ de carbonato de bário $\left(\mathrm{BaCO}_{3}\right)$ e $80 \%$ de carvão vegetal. As caixas foram seladas com argila, evitando assim o contato com a atmosfera e mantendo o potencial de carbono do cemento no interior da caixa.

Em seguida, as caixas seladas foram levadas ao forno do tipo mufla à temperatura de $900^{\circ} \mathrm{C}$, com tempos de estágio distintos, nomeadamente $6 \mathrm{~h}, 11 \mathrm{~h}$ e $24 \mathrm{~h}$. Cumpridas as horas previstas para a realização da cementação, as amostras foram resfriadas no interior do forno. Uma amostra de cada tempo foi arquivada para que fosse possível 
analisar os corpos de prova na forma em que se encontravam logo após a cementação, ainda sem tratamento térmico posterior.

Nas demais amostras foram realizados os tratamentos térmicos de têmpera e revenimento. A têmpera foi feita à temperatura de $850^{\circ} \mathrm{C}$, com tempo de estágio de 30 minutos, seguido de resfriamento em óleo. O revenimento foi realizado à temperatura de $180^{\circ} \mathrm{C}$ com tempo de estágio de 20 minutos e posterior resfriamento ao ar. $\mathrm{O}$ esquema do procedimento experimental está apresentado na Figura 1.

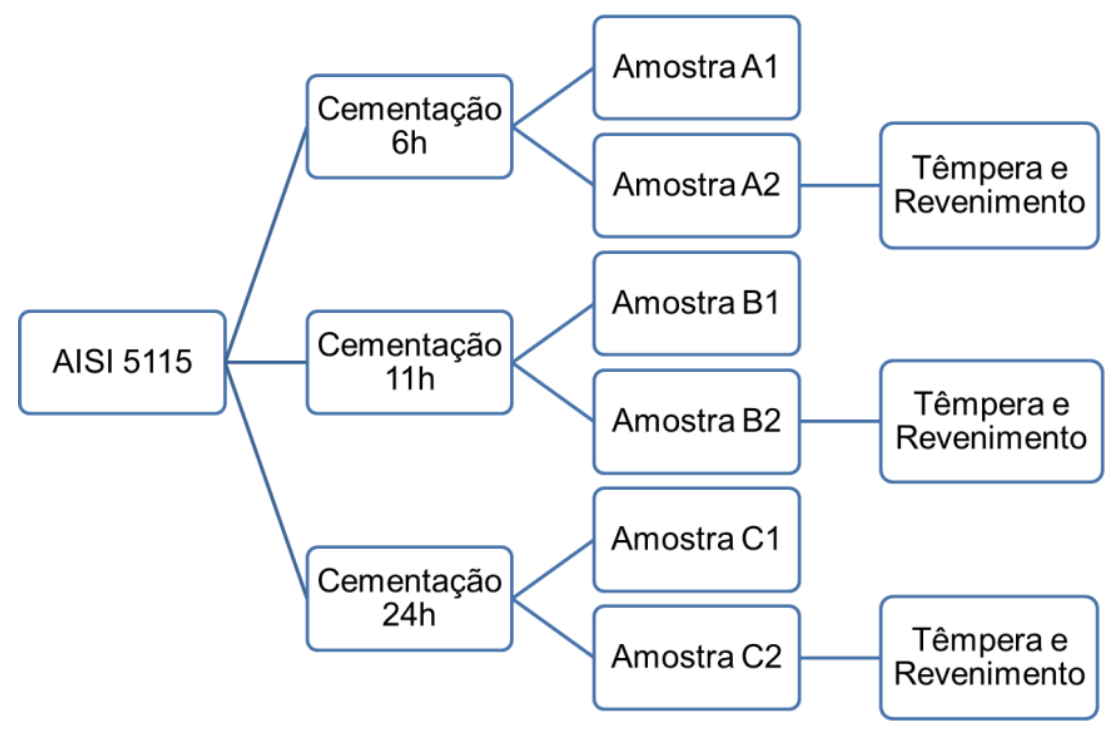

Figura 1: Esquema do procedimento experimental.

\subsubsection{Ensaio de microdureza e análise metalográfica}

O ensaio de microdureza Vickers foi realizado de acordo com a norma ASTM E384 11e1 [10].

As amostras do material de base e as submetidas aos tratamentos termoquímicos passaram pelo processo de lixamento e polimento metalográfico padrão. Em seguida, foram atacadas pelo reativo Nital $2 \%$, com tempo de imersão entre $7 \mathrm{~s}$ a $15 \mathrm{~s} . \mathrm{Na}$ análise microestrutural, utilizou-se um microscópio óptico Zeiss Axiotech 100 HD do no laboratório de Engenharia Metalúrgica e de Materiais da Faculdade de Engenharia da Universidade do Porto. Para fins de comparação, foram analisadas as superfícies da amostra de base e das amostras submetidas aos tratamentos termoquímicos.

\section{RESULTADOS E DISCUSSÃO}

A microestrutura do material de base foi inicialmente caracterizada, sendo constituída por uma matriz ferrítica, fase mais clara, e por colônias de perlita, mais escuras, como identificado na Figura 2 [11]. 


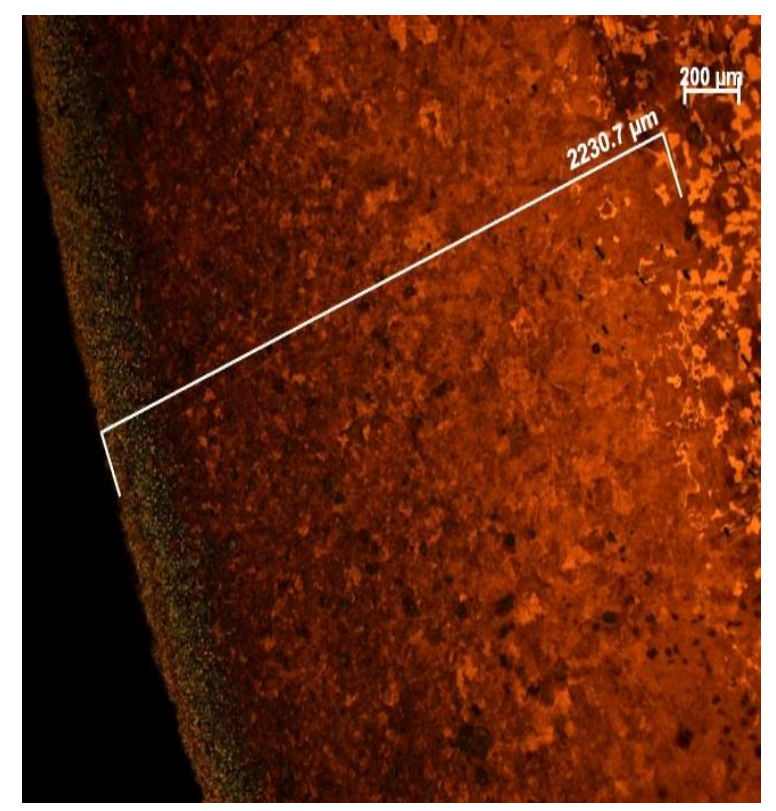

Figura 5: Profundidade da camada cementada, tempo de 24h.

Nota-se, na Figura 6, regiões com concentrações de carbono distintas. A região mais próxima à superfície apresenta a máxima quantidade de carbono da amostra. Esse valor é limitado pela temperatura de cementação, $900^{\circ} \mathrm{C}$, e pela concentração de carbono presente. Segundo o diagrama de fases ferro-cementita, com essa composição química e à temperatura considerada, o aço intercepta a linha $A_{c m}$. Em seu resfriamento formam-se, portanto, os constituintes cementita e perlita, considerando a grande disponibilidade de carbono no aço em questão. Avançando para o interior da amostra, a quantidade de cementita diminui e a de perlita aumenta, devido à diminuição de carbono disponível no meio. Pode-se perceber o aumento do tamanho de grão devido ao sobreaquecimento da região. Esse fenômeno ocorre, pois essa área foi submetida a temperaturas muito superiores à de transformação.

$\mathrm{Na}$ Figura 7, mais ao interior da amostra, há uma região onde existe aglomeração de perlita, permitindo concluir que o teor de carbono está próximo ao do eutetoide. Avançando, observa-se perlita e ferrita. Credita-se a presença desta última fase à diminuição do teor em de carbono, ultrapassando o ponto eutetoide. Não se observa crescimento de grão pois essa região não estava sob efeito de sobreaquecimento. Atingindo-se o valor $81,1 \%$ de ferrita e $18,9 \%$ de perlita, chega-se à proporção apresentada pelo material de base. 


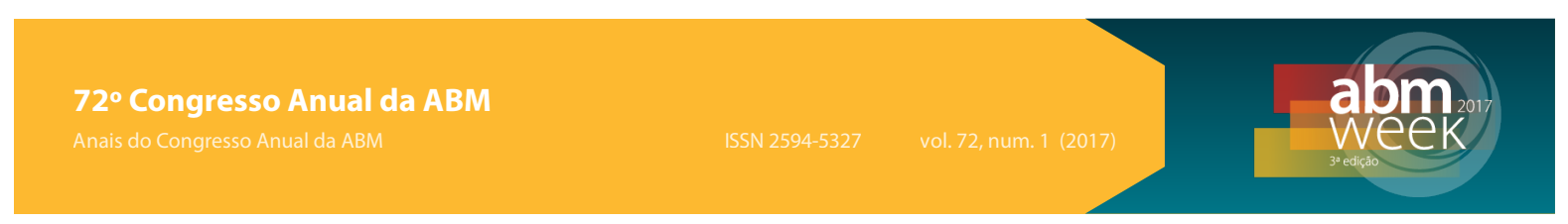

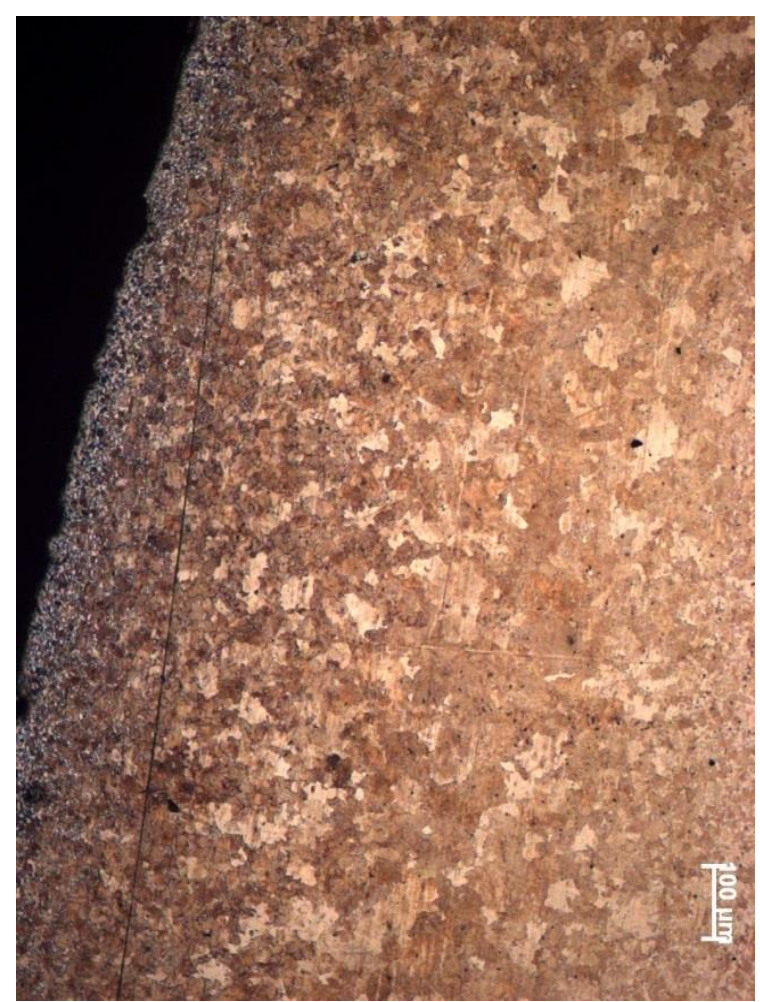

Figura 6: Microestrutura superficial da capa cementada, tempo de $6 \mathrm{~h}$. Nital $2 \%$.

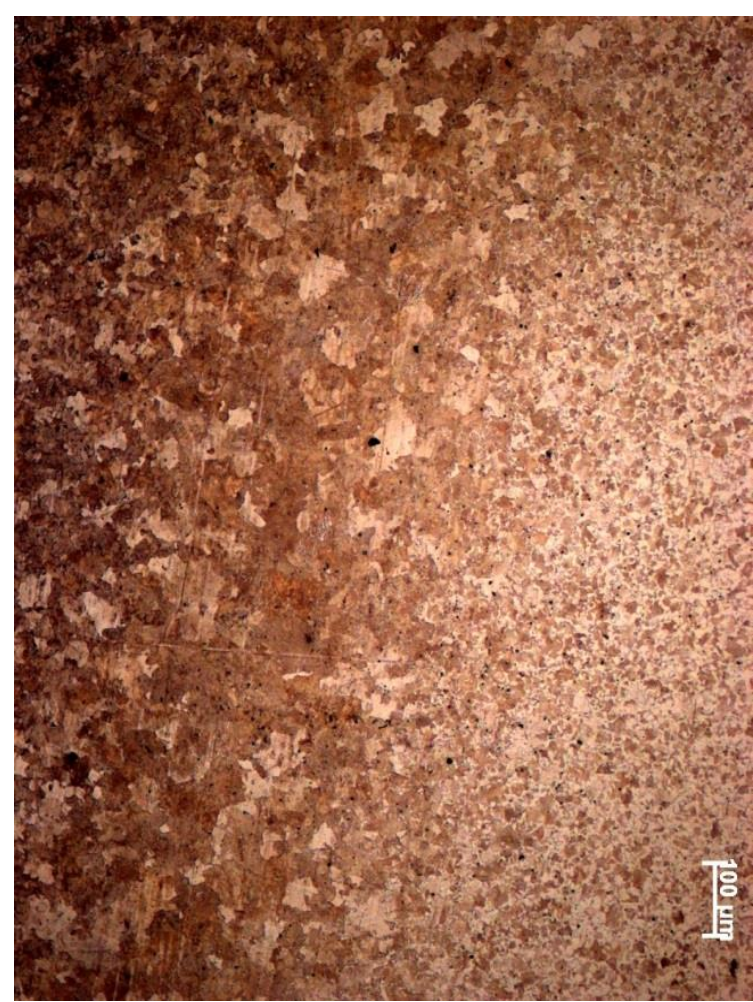

Figura 7: Microestrutura mais ao interior e fim da capa cementada, tempo de $6 \mathrm{~h}$. Nital $2 \%$.

Uma maneira de certificar a relação direta entre o tempo de cementação e a profundidade da capa cementada é utilizando a Lei de Fick, apresentada na Equação 1. Para efeitos de cálculo, estimou-se o valor de $\mathrm{Cx}$, teor de carbono à distância $\mathrm{x}$ da periferia, por um acima ao da liga de base, que permitirá uma maior diferença na dureza. Calculou-se o coeficiente de difusidade $D=1,46 \times 10^{-11} \mathrm{~m}^{2} / \mathrm{s}$ a partir da equação 2, considerando $\mathrm{T}=1173 \mathrm{~K}, \mathrm{R}=8,314 \mathrm{~J} / \mathrm{mol} . \mathrm{K}, \mathrm{Q}=135 \mathrm{KJ} / \mathrm{mol}$ e $\mathrm{Do}=1,5 \times 10^{-5}$ $\mathrm{m}^{2} / \mathrm{s}$. Utilizando-se $\mathrm{Cx}=0,2 \% \mathrm{p}, \mathrm{Co}_{\mathrm{o}}=0,16$ e $\mathrm{Cs}=1,21$ para cada tempo, obteve-se os resultados apresentados na Tabela 2, que confirmam essa tendência.

Tabela 2. Valores da profundidade da camada cementada.

\begin{tabular}{cc}
\hline Tempo $(\mathbf{h})$ & Profundidade da camada cementada $(\boldsymbol{\mu m})$ \\
\hline 6 & 1639,5 \\
\hline 11 & 2219,2 \\
\hline 24 & 3279,16 \\
\hline
\end{tabular}

Como a porcentagem de carbono varia para o interior da amostra, espera-se que a microestrutura também se altere. Essa variação não ocorre de forma aleatória, mas sim seguindo as transformações previstas pelo diagrama de equilíbrio ferro-cementita. Utilizando a regra da alavanca, pode-se estimar a porcentagem de perlita e cementita, que são $92,65 \%$ e $7,45 \%$, respectivamente.

Consegue-se averiguar essa ideia utilizando a Lei de Fick, Equação 1. Sabe-se que o limite da capa dura é estabelecido à dureza de $550 \mathrm{Hv}$ [7]. Por este dado, pode-se calcular o teor de carbono no limite da capa, utilizando a Equação 3:

$$
H R C=60 \sqrt{\% C}+20
$$


Em que HRC é a dureza em Rockwell C e \%C é o teor em carbono. O valor encontrado para o teor de carbono foi 0,29 .

Dados $\mathrm{T}=1173 \mathrm{~K}, \mathrm{R}=8,314 \mathrm{~J} / \mathrm{mol} . \mathrm{K}, \mathrm{Q}=135 \mathrm{KJ} / \mathrm{mol}$ e $\mathrm{Do}=1,5 \times 10^{-5} \mathrm{~m}^{2} / \mathrm{s}$ e substituindo na Equação 2, tem-se o coeficiente de difusidade $D=1,46 \times 10^{-11} \mathrm{~m}^{2} / \mathrm{s}$. Dessa forma, utilizando $\mathrm{Co}=0,16, \mathrm{Cx}=0,29, \mathrm{Cs}=1,21$ e os tempos de cementação na Lei de Fick, Equação 1, obteve-se os valores de profundidade da capa dura, presentes na Tabela 3 a seguir. Inferiu-se que quanto maior o tempo maior foi a profundidade da capa dura originada.

Tabela 3. Valores da profundidade da camada cementada

\begin{tabular}{cc}
\hline Tempo $(\mathbf{h})$ & Profundidade da camada cementada $(\boldsymbol{\mu m})$ \\
\hline 6 & 1224,07 \\
\hline 11 & 1657,6 \\
\hline 24 & 2445,4 \\
\hline
\end{tabular}

As amostras cementadas, que posteriormente sofreram têmpera e revenido, foram submetidas a ensaios de microdureza com o objetivo de construir seus perfis de dureza. Nesse caso, a martensita revenida é o constituinte responsável por conferir dureza ao aço. Por norma, considera-se que o material foi temperado quando este apresenta dureza igual ou superior a $550 \mathrm{Hv} / 9.81 \mathrm{~N}$. O mesmo critério é utilizado para estabelecer o limite de profundidade da camada dura, permitindo medir sua espessura perpendicularmente à superfície, desde a periferia em direção ao centro.

Uma maneira de estimar a profundidade da camada cementada é observar nas curvas de dureza, Figura 8, a distância em que os valores se estabilizam, atingindo grandezas semelhantes aos do interior da amostra. A dureza está relacionada à composição química do aço. No caso, por ser um aço não ligado, sua dureza é dependente do teor de carbono de forma proporcional. Então, o decaimento da dureza indica também uma diminuição do teor de carbono. Pode-se verificar no gráfico da Figura 8 que, quanto maior o tempo de cementação, maior a distância da capa cementada. 


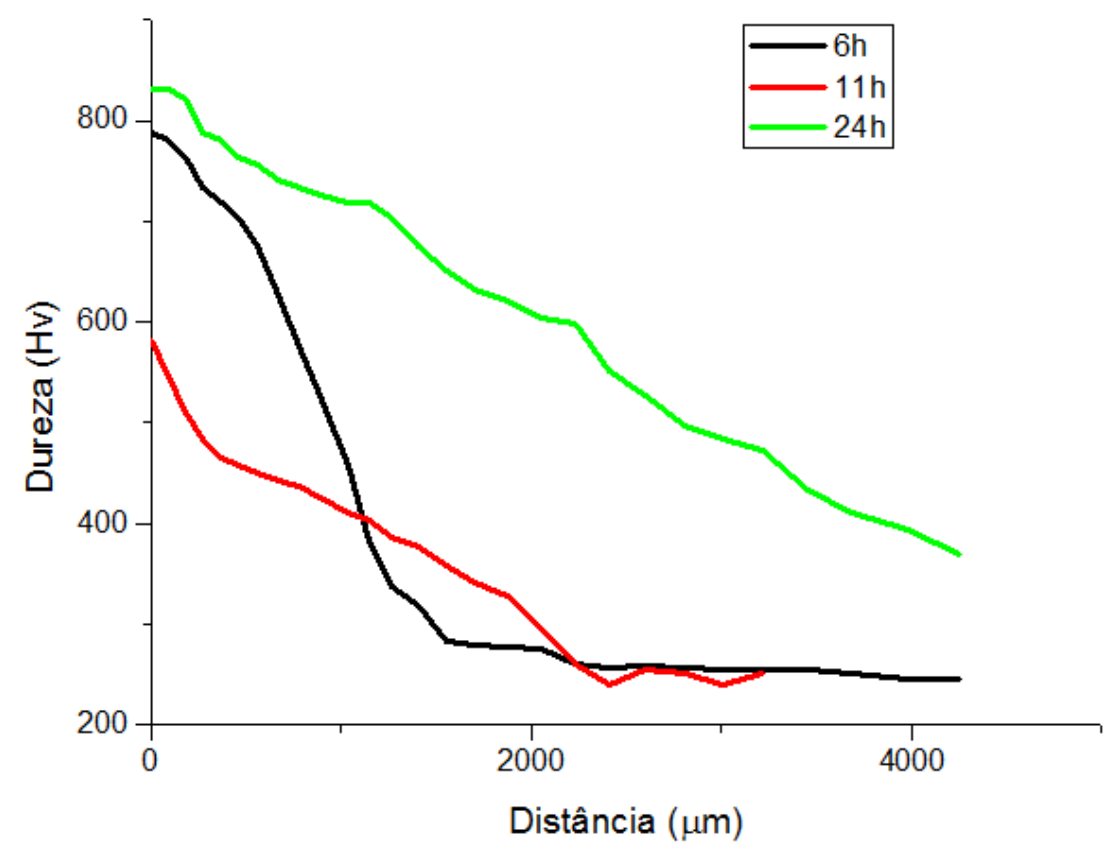

Figura 8: Perfis de dureza das amostras cementadas por $6 \mathrm{~h}, 11 \mathrm{~h}$ e $24 \mathrm{~h}$.

Sabe-se que, quanto maior o tempo, maior a difusão do carbono. O teor em carbono difundido para o interior da amostra condiciona a transformação em martensita, que é responsável pela elevada dureza nessa região. Logo, quanto maior o tempo, maior a região endurecida e maior será a camada dura, como pode ser observado nos perfis de dureza presentes na Figura 8, apresentada anteriormente.

É possível que se faça uma comparação entre os valores da camada endurecida previstos pela Lei de Fick e aqueles obtidos pelo perfil de dureza, conforme Figura 9. Esses valores são muito próximos, ressaltando a validade da teoria em relação à difusão do carbono. Apenas na amostra submetida à cementação por $11 \mathrm{~h}$ há uma pequena disparidade de valores, o que pode ser atribuído à uma descarbonetação da superfície do material. Esta amostra apresentou dureza superficial mais baixa que as demais, reforçando ainda mais a hipótese anteriormente apresentada.

Já na Figura 10, a comparação é feita entre os valores de profundidade da camada cementada. Em todas as condições ocorreu um aumento de profundidade com o tempo de cementação, complementando e reforçando os resultados anteriores. 


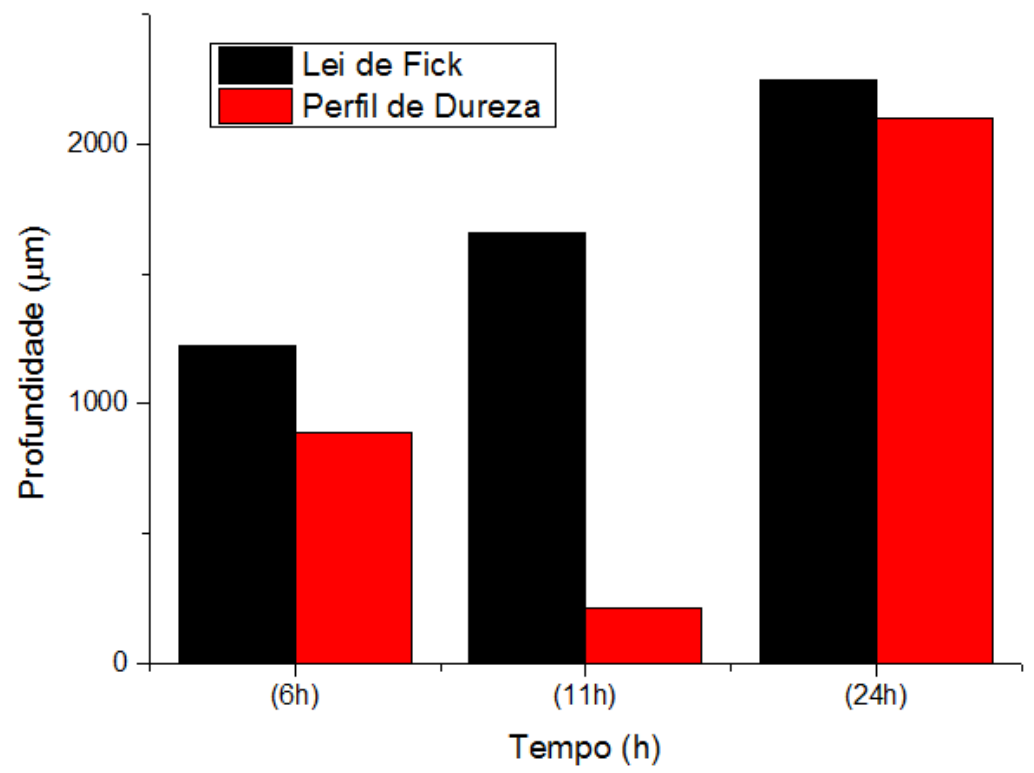

Figura 9. Comparação dos valores da camada endurecida obtidas pela Lei de Fick e pelo perfil de dureza

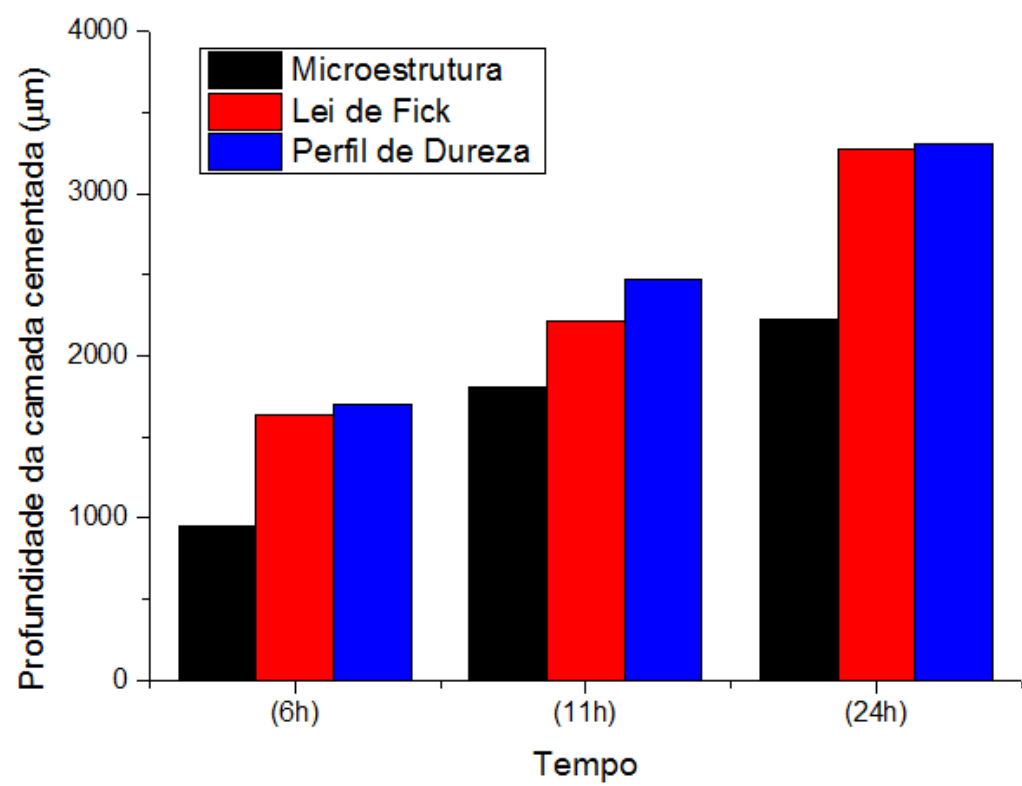

Figura 10. Comparação dos valores da camada cementada obtidas pela microestrutura, pela Lei de Fick e pelo perfil de dureza.

\section{CONCLUSÃO}

Por meio deste trabalho, foi possível concluir que o tempo de cementação está intimamente ligado à profundidade da camada endurecida. Através da avaliação da segunda Lei de Fick, pelos perfis de dureza das amostras e pela análise da 
microestrutura encontrada, foi possível constatar que a camada endurecida aumenta com o tempo de tratamento.

Em termos práticos, a profundidade da camada cementada será condicionada de acordo com as especificações da aplicação à qual o aço se destina. Assim, peças que necessitam de maior resistência mecânica superficial serão submetidas a maiores tempos de cementação.

Observou-se também a possível ocorrência de descarbonetação na amostra submetida a $11 \mathrm{~h}$ horas de tratamento, visto que apresentou menores valores de dureza na região mais superficial dos corpos de prova.

\section{Agradecimentos}

Agradecemos ao Conselho Nacional de Desenvolvimento Científico e Tecnológico (CNPq) pelo auxílio financeiro durante o período de intercâmbio na Faculdade de Engenharia da Unviersidade do Porto, realizado por meio do programa Ciência sem Fronteiras entre os anos de 2012 e 2013.

\section{REFERÊNCIAS}

1 ASM Metals Handbook, 1991. Heat Treating, ASM International, v. 4. 1991

2 Giordani T. Avaliação metalúrgica e mecânica de aços cementados e temperados de forma convencional e intensiva. Dissertação (Mestrado em Engenharia) - Universidade Federal do Rio Grande do Sul, Porto Alegre, 2012.

3 Chiaverini, V. Tratamentos térmicos das ligas metálicas.7 ed. São Paulo: Associação Brasileira de Metalurgia e Materiais; 2008.

4 Scheuer CJ. Comportamento tribológico e resistência à corrosão do aço inoxidável martensítico AISI 420 cementado por plasma a baixa temperatura. Tese (Doutorado em Engenharia Mecânica) - Universidade Federal do Paraná, Curitiba, 2015.

5 Czerwinski F. Heat treatment - conventional and novel applications - Chapter 5: Thermochemical Treatment of Metals, 2012.

6 Krauss G. Steels: heat treatment and processing principles, 5 ed. Ohio: ASM International; 1997

7 Callister WD. Materials science and engineering. 7 ed. Nova lorque: John Wiley \& Sons; 2007.

8 Celestino PAP, Felipe RCTS, Machado TG. Análise comparativa entre o tratamento térmico têmpera e o tratamento termoquímico cementação realizado em aço 1040. Holos. 2007;3: 223-232.

9 Catálago Ramada Aços: Special steel solutions . Disponível em: http://www.ramada.pt/ficheiros_upload/ramada-aa-os---catalogo2014160530113811.pdf. Acessado em 19 de junho de 2017.

10 ASTM E384-11e1 - Standard Test Method for Knoop and Vickers Hardness of Materials, 2011

11 Colpaert H.; Silva, A. L. C. Metalografia dos produtos siderúrgicos comuns. 4 ed. São Paulo: Blücher; 2008. 